\title{
Castleman's Disease: An Intrapulmonary Form with Intrafissural Development
}

\author{
Hajer Racil $^{1}$, Sana Cheikh Rouhou ${ }^{1, *}$, Olfa Ismail ${ }^{2}$, \\ Saoussen Hantous-Zannad ${ }^{3}$, Nawel Chaouch ${ }^{1}$, Mourad Zarrouk ${ }^{1}$, \\ Belhassen Smati ${ }^{4}$, Faouzi Mezni ${ }^{2}$, and Abdellatif Chabbou ${ }^{1}$ \\ ${ }^{1}$ Pulmonology Department, Pavillon $1 / ;{ }^{2}$ Pathology Department; ${ }^{3}$ Radiology \\ Department; ${ }^{4}$ Thoracic Surgery Department; Abderrahman Mami Hospital, Ariana, \\ Tunisia \\ E-mail: sana.cheikhrouhou@gmail.com
}

Received April 29, 2009; Revised September 1, 2009; Accepted September 1, 2009; Published September 14, 2009

Castleman's disease (CD) is an uncommon, mainly benign, lymphoproliferative disorder of unknown etiology, mostly involving the mediastinum. Parenchymal lung involvement of the disease is exceedingly rare. We describe a case of CD in a 23-year-old woman with a 4-year history of recurring dyspnea and nonproductive cough, whose chest X-ray showed an abnormal shadow of the right hilum. Chest computed tomography confirmed the presence of a tissue-density mass of the right lower lobe, demonstrating poor contrast enhancement, associated with multiple laterotracheal and mediastinal lymphadenopathies. The patient underwent curative surgery, revealing a right hilar compressive mass, with an intrafissural development between the superior and middle lobes. Pneumonectomy was performed due to profuse bleeding. This case of CD is particular because of its unusual intrapulmonary location and its intrafissural development. Poor contrast enhancement is atypical in CD.

KEYWORDS: Castleman, angiofollicular hyperplasia, pulmonary, interlobar fissure

\section{BACKGROUND}

Castleman's disease (CD), also known as angiofollicular lymph node hyperplasia, was first described in 1954 by Dr. Benjamin Castleman at Massachusetts General Hospital[1].

$\mathrm{CD}$ is an uncommon, mainly benign, lymphoproliferative disorder of unknown etiology, mostly involving the mediastinum[2]. CD could be categorized into two clinical types: unicentric (or localized form) and multicentric (or systemic form) $[3,4]$. Three distinct histological variants are recognized: the hyaline vascular (HV) type (seen in $90 \%$ of cases), the plasma cell (PC) type (8-9\% of cases), and an intermediary "mixed" type (1-2\% of cases)[3,5]. Parenchymal lung involvement of the disease is exceedingly rare[2,6].

We report herein a case of unicentric $\mathrm{CD}$, with isolated intrapulmonary involvement and intrafissural development, in a patient who underwent curative surgery. 


\section{CASE REPORT}

A 23-year-old, nonsmoking woman, with a familial history of atopy, presented to our department due to a 4-year history of recurring dyspnea and intermittent cough. Chest X-ray film revealed a 4-cm parahilar opacity (Fig. 1). Chest computed tomography (CT) confirmed the presence of a homogenous tissuedensity mass, $4.4 \times 2.8 \mathrm{~cm}$, located in the right interbronchial space, compressing contiguous vascular and bronchial structures. This mass is associated to subcarinal lymphadenopathies and to infracentimetric lymph nodes located in both right and left laterotracheal chains and in the anterior mediastinum. The mass demonstrated poor contrast enhancement (CE); its origin could not be ruled out, but was most consistent with a voluminous interbronchial lymphadenopathy (Figs. 2A,B).

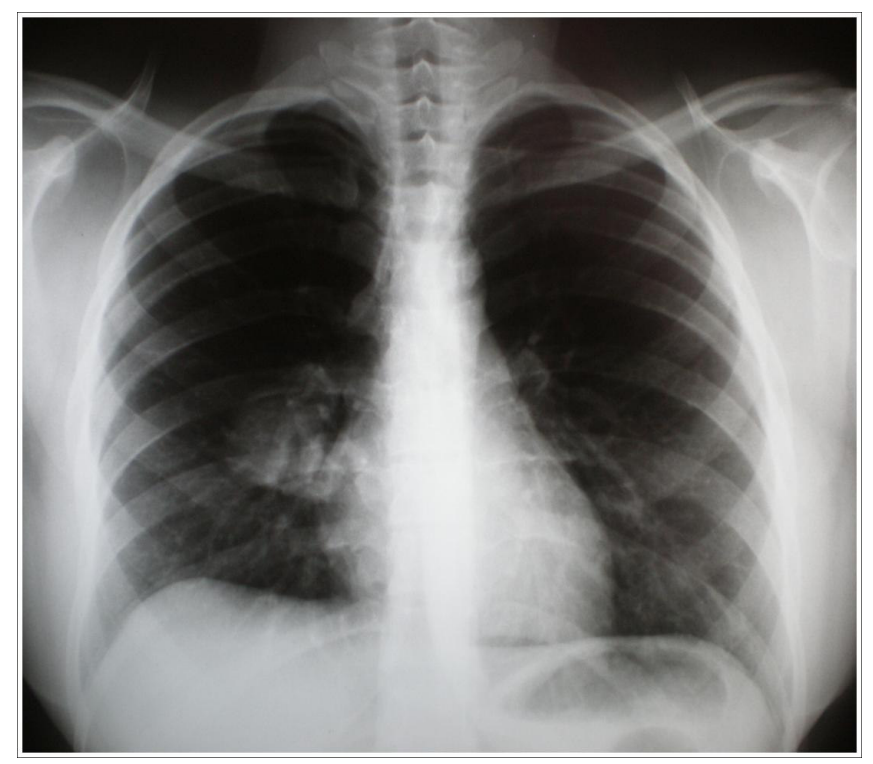

FIGURE 1. Chest X-ray film showing a 4-cm parahilar opacity.

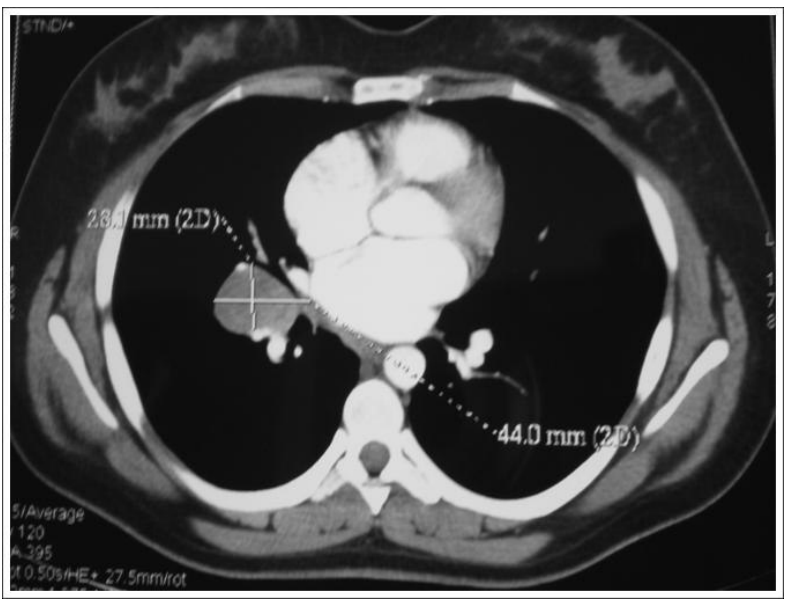

A

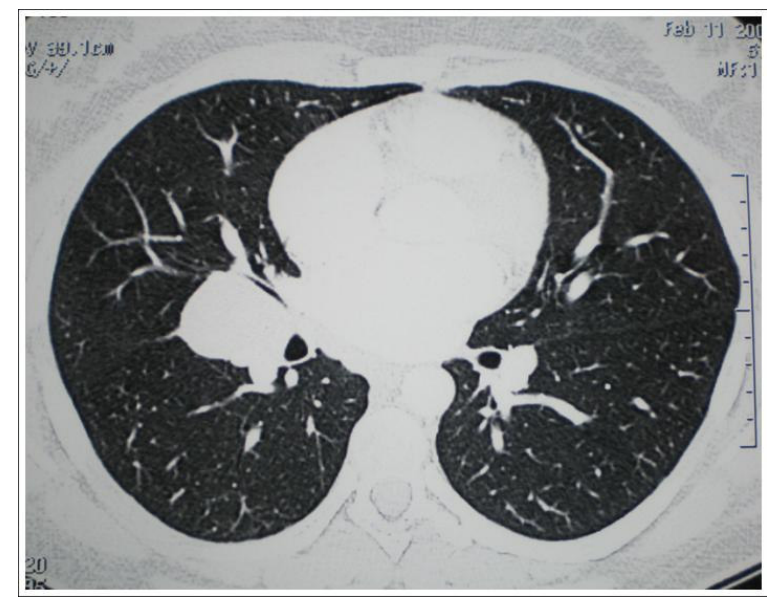

B

FIGURE 2. CT scan of the chest. (A) Presence of a homogenous tissue-density mass, $4.4 \times 2.8 \mathrm{~cm}$, located in the right interbronchial space and presenting poor CE. (B) The mass is compressing contiguous bronchial structures. 
Physical examination revealed no abnormalities. Laboratory investigations were within the normal range, except an elevated C-reactive protein rate at $22.6 \mathrm{mg} / \mathrm{l}$. Bronchoscopy showed a bronchial compression at the entry of the right middle lobe.

A right posterior thoracotomy was performed and revealed a $4.5-\mathrm{cm}$ well-defined right hilar mass, with an intrafissural development between the superior and middle lobes. The tumor lesion tightly compressed the middle lobe bronchus and the intrafissural portion of the pulmonary artery. Rapid cytological analysis was intended, but due to profuse bleeding at attempt, and given the tumoral extension to both lobes, a right pneumonectomy was rapidly decided, with total ganglionic subcarinal curage and partial ganglionic resection of the Barety space.

Histopathological examination showed presence of characteristic HV follicles, regularly distributed on a background of lymphocytes (Fig. 3A). The lymphoid follicles present onion-like arranged lymphocytes and interfollicular capillary proliferations. The concentric rings of lymphocytes surround a small atrophic germinal center where an endothelial vascular hyperplasia is observed (Fig. 3B).

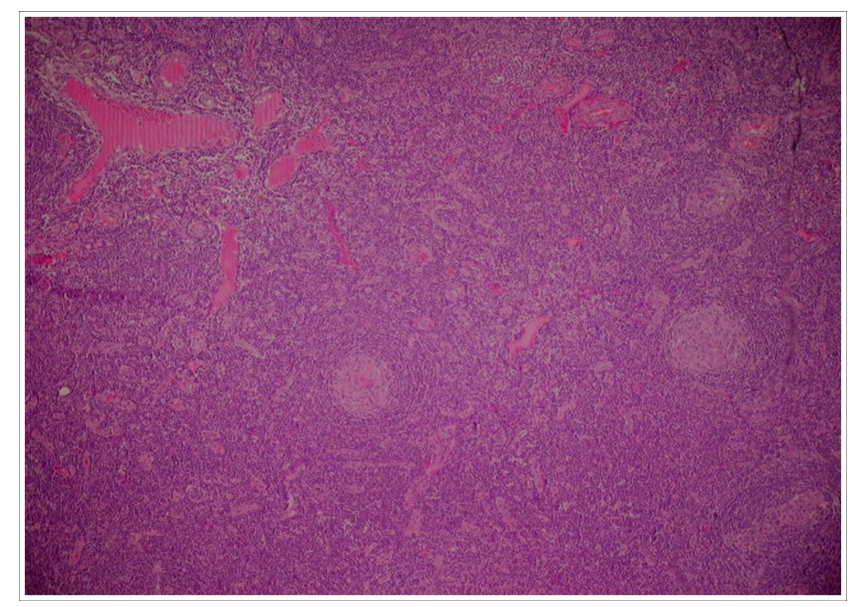

A

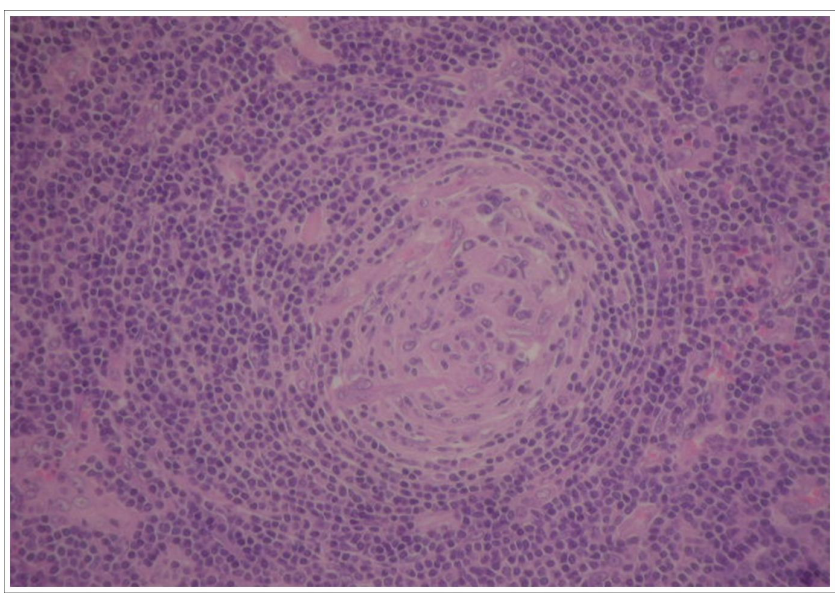

B

FIGURE 3. Histopathologic examination showing angiofollicular hyperplasia. (A) The characteristic histological pattern is produced by a great number of lymphoid follicles regularly distributed on a background of lymphocytes. (B) A detail of the enlarged lymphoid follicle shows that the central vessels present thick walls and that the endothelial cells are prominent. 
A histological diagnosis of benign giant lymph node hyperplasia of the lung corresponding to the HV type of CD was made. Histology of resected lymph nodes was inflammatory. Both HIV-serology and a protein electrophoresis were performed and were normal. The patient has remained well, with no recurrence of symptoms or signs for 1 year.

\section{DISCUSSION}

In this case, unicentric CD presented as a well-defined pulmonary mass, developing in the right interlobar fissure. To our knowledge, isolated parenchymal pulmonary involvement is very rare in CD; a handful of cases have previously been reported. Usually, the disease manifests as a solitary pulmonary nodule[2,6,7,8,9,10,11]. Intrafissural development, as observed in our patient, is an original observation; review of published literature revealed a unique similar case report[12].

The etiology of CD is poorly understood. Danon et al. suggested that the HV type may originate from an antigen stimulus involving a lymph node containing abnormal plasmacytoid monocytes[13].

Unicentric CD has no race or sex predilection and may occur at any age, with a median age at diagnosis of 20 years (range: 8-66 years)[5,14,15]. Clinical and biological manifestations are usually absent; the disease is typically diagnosed through incidental radiological findings in $95 \%$ of cases $[5,15,16]$. The most frequent histological variant encountered in unicentric CD is the HV type[3,5]. The latter is usually asymptomatic, although cases of immunoglobulin and serologic abnormalities have been noted, as well as rare instances of hypochromatic anemia, cytopenia, and thrombocytopenia[17].

CD characteristically affects nodes and originates from the thorax, although the disease can arise wherever lymphoid tissue is found[2]. In up to $15 \%$ of cases, extrathoracic involvement is observed and mainly affects the neck, retroperitoneum, and mesentery[5,18]. In 5\% of cases, the disease is extranodal[13] and may affect visceral organs, including the liver, spleen, pancreas, and adrenals[19,20], or tissues such as the larynx, parotid gland, various muscles, and cranium[20].

Despite evidence suggesting that thoracic CD usually originates from the lymph nodes along the tracheobronchial tree, some authors found that atypical thoracic localizations (defined as tumors located other than in the mediastinum or pulmonary hilum) accounted for up to $30 \%$ of unicentric thoracic CD. Interestingly, only one case of these originated from the lung, which further emphasizes the rarity of isolated intrapulmonary $\mathrm{CD}$ [7]. Atypical thoracic localizations of $\mathrm{CD}$ include the pleura, axilla, supraclavicular fossa, intercostal space, and pericardium[7,21].

Thoracic unicentric CD typically manifests as a well-defined, rounded, mediastinal or hilar mass of soft tissue density, featuring intense and homogenous contrast enhancement (CE) after medium contrast injection, by virtue of its hypervascular nature[7,14]. However, thoracic CD may arise from unusual localizations[22,23] and occasionally exhibits atypical appearances on CT and MR imaging, as in our patient. Atypical enhancement is defined as poor contrast, target, or concentric enhancement patterns on $\mathrm{CT}$ and/or MR imaging[7]. In our case, the mass showed poor CE, which explains why the diagnosis was not considered preoperatively.

Pathologic diagnosis of $\mathrm{CD}$ may pose some difficulty. It may mimic other lymphoproliferative disorders in their clinical presentation and morphologic appearance, such as histiocytic sarcoma[24]. In some cases, the latter may be associated with CD, usually the HV type[25].

The surgical approach is usually curative in unicentric CD, but is usually associated with profuse bleeding[26] due to the hypervascularity of these tumors. This propensity to bleed accounts for the difficulty in intraoperative management of $\mathrm{CD}$, and resulted in a total right pneumonectomy in our patient. A few previous reports have reported that preoperative arterial embolization minimized intraoperative bleeding[26] and made the surgical management safer.

$\mathrm{CD}$, despite its rarity and in view of the increasing numbers of reported parenchymal lung involvement of the disease, should be considered in the differential diagnosis of asymptomatic or oligosymptomatic pulmonary nodules. 


\section{ACKNOWLEDGMENT}

I would like to acknowledge and thank TheScientificWorldJOURNAL Editor.

\section{REFERENCES}

1. Castleman, B. and Towne, V. (1954) Case records of the Massachusetts General Hospital: case n ${ }^{\circ} 40231 . ~ N$. Engl. J. Med. 250, 1001-1005.

2. Ferrozzi, F., Tognini, G., Spaggiari, E., and Pavone, P. (2001) Focal Castleman disease of the lung: MRI findings. Clin. Imaging 25(6), 400-402.

3. Dham, A. and Peterson, B.A. (2007) Castleman disease. Curr. Opin. Hematol. 14(4), 354-359.

4. Dispenzieri, A. and Gertz, M.A. (2005) Treatment of Castleman's disease. Curr. Treat. Options Oncol. 6(3), $255-266$.

5. Keller, A.R., Hochholzer, L., and Castleman, B. (1972) Hyaline vascular and plasma cell types of giant lymph node hyperplasia of the mediastinum and other locations. Cancer 29, 670-683.

6. Yeh, C.M., Chou, C.M., and Wong, L.C. (2007) Castleman's disease mimicking intrapulmonary malignancy. Ann. Thorac. Surg. 84(2), e6-7.

7. Ko, S.F., Wan, Y.L., Ng, S.H., Lin, J.W., Hsieh, M.J., Fang, F.M., Lee, T.Y., and Chen, W.J. (2004) Imaging features of atypical thoracic Castleman disease. Clin. Imaging 28(4), 280-285.

8. Awotedu, A.A., Otulana, B.A., and Ukoli, C.O. (1990) Giant lymph node hyperplasia of the lung (Castleman's disease) associated with recurrent pleural effusion. Thorax 45, 575-576.

9. Barrie, J.R., English, J.C., and Muller, N. (1996) Castleman's disease of the lung: radiographic, high resolution CT and pathologic findings. AJR Am. J. Roentgenol. 166, 1055-1056.

10. Spedini, S., Lombardi, C., Lanzani, G., Di Fabio, D., and Chiodera, P.L. (1995) Castleman's disease presenting as an asymptomatic solitary pulmonary nodule. Monaldi Arch. Chest Dis. 50, 363-365.

11. Krawczun, G.A., Garcia Cde, M., Ito, K., Ferreira Filho, O.F., and Thomson, J.C. (2007) Castleman's disease or angiofollicular hyperplasia as a solitary pulmonary nodule: case report. J. Bras. Pneumol. 33(2), 226-228.

12. Caus, T., Leude, E., Thomas, P., Garbe, L., Giudicelli, R., and Fuentes, P. (1992) Castleman's disease. An intrapulmonary isolated form with fissural exteriorization. Presse Med. 21(20), 934-936.

13. Danon, A.D., Krishnan, J., and Frizzera, G. (1993) Morphoimmunophenotypic diversity of Castleman disease, hyaline vascular type: with emphasis on stroma-rich variant and a new pathogenetic hypothesis. Virchows Arch. A Pathol. Anat. Histopathol. 20,363-347.

14. McAdams, H.P., Rosado-de-Christenson, M., Fishback, N.F., and Templeton, P.A. (1998) Castleman disease of the thorax: radiologic features with clinical and histopathologic correlation. Radiology 209, 221-228.

15. Seirafi, P.A., Ferguson, E., and Edwards, F.H. (2003) Thoracoscopic resection of Castleman disease: case report and review. Chest 123(1), 280-282.

16. Colchen, A., Personne, C., Audebaud, G., Toty, L., and Hertzog, P. (1991) Memoires originaux: les formes médiastinales de la maladie de Castleman. A propos de 3 observation. Rev. Fr. Mal. Respir. 8, 103-106.

17. Peterson, B.A. and Frizzera, G. (1993) Multicentric Castleman's disease. Semin. Oncol. 20, 636-647.

18. Bowne, W.B., Lewis, J.J., Filippa, D.A., et al. (1999) The management of unicentric and multicentric Castleman's disease: a report of 16 cases and a review of the literature. Cancer 85, 706-717.

19. Debatin, G.F., Spritzer, C.E., and Dunnich, N.R. (1991) Castleman disease of the adrenal gland: MR imaging features. AJR Am. J. Roentgenol. 157, 781-783.

20. Kim, T.J., Han, J.K., Kim, Y.H., Kim, T.K., and Choi, B.I. (2001) Castleman disease of the abdomen: imaging spectrum and clinicopathologic correlations. J. Comput. Assist. Tomogr. 25, 207-214.

21. Mohanna, S., Sanchez, J., Ferrufino, J.C., Bravo, F., and Gotuzzo, E. (2006) Characteristics of Castelman's disease in Peru. Eur. J. Intern. Med. 17, 170-174.

22. Reynolds, S.P., Gibbs, A.R., Weeks, R., Adams, H., and Davies, B.H. (1992) Massive pleural effusion: an unusual presentation of Castleman's disease. Eur. Respir. J. 5, 1150-1153.

23. Rena, O., Casadio, C., and Maggi, G. (2001) Castleman disease: unusual intrathoracic localisation. Eur. J. Cardiothorac. Surg. 19, 512-519.

24. Alexiev, B.A., Sailey, C.J., McClure, S.A., Ord, R.A., Zhao, X.F., and Papadimitriou, J.C. (2007) Primary histiocytic sarcoma arising in the head and neck with predominant spindle cell component. Diagn. Pathol. 2, 7.

25. (2001) World Health Organization Classification of Tumors: Pathology and Genetics of Tumours of Haematopoietic and Lymphoid Tissue. IARC Press, Lyon, France. pp. 274-289.

26. Robert, J.H., Sgourdos, G., Kritikos, N., Didier, D., and Terraz, S. (2008) Preoperative embolization of hypervascular Castleman's disease of the mediastinum. Cardiovasc. Intervent. Radiol. 31(1), 186-188. 
This article should be cited as follows:

Racil, H., Cheikh Rouhou, S., Ismail, O., Hantous, S., Chaouch, N., Zarrouk, M., Smati, B., Mezni, F., and Chabbou, A. (2009) Castleman's disease: an intrapulmonary form with intrafissural development. TheScientificWorldJOURNAL 9, 940-945. DOI 10.1100/tsw.2009.110. 


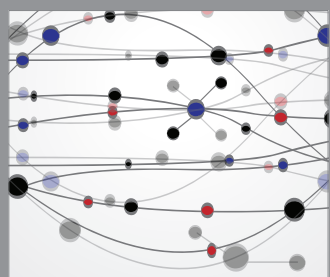

The Scientific World Journal
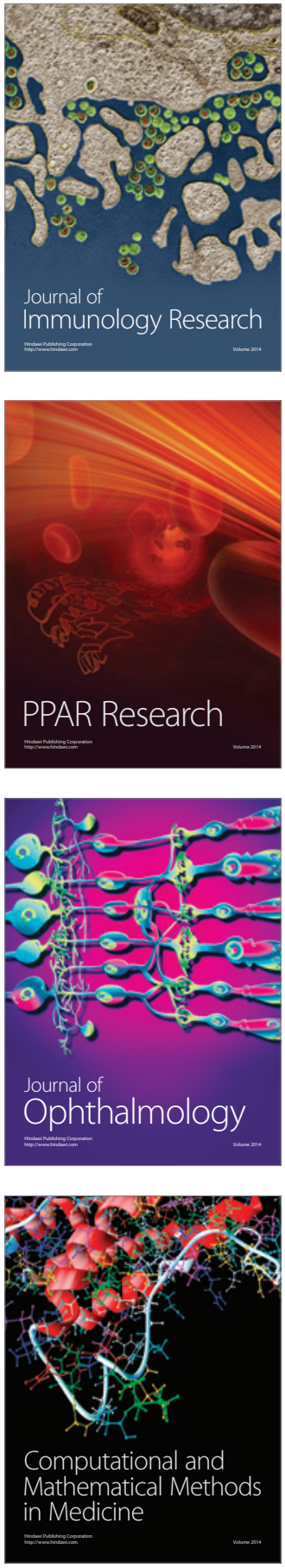

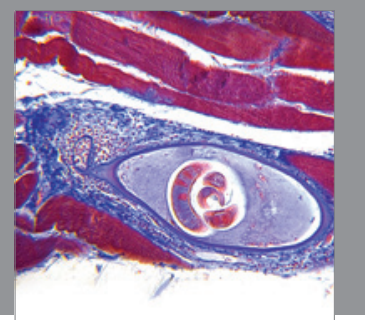

Gastroenterology

Research and Practice
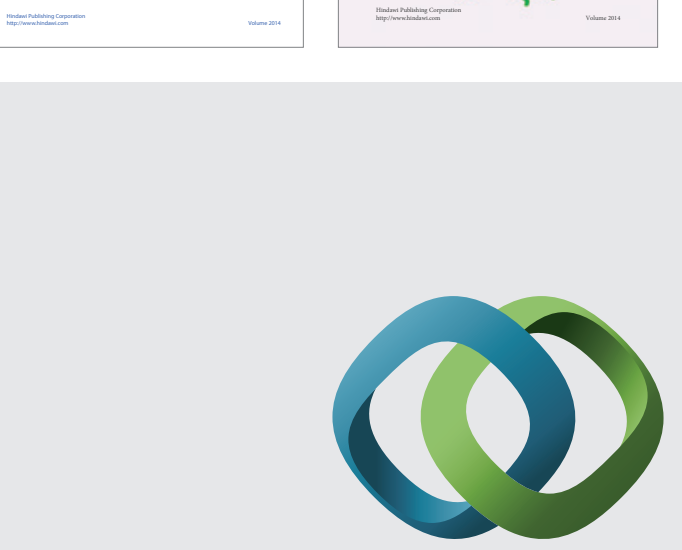

\section{Hindawi}

Submit your manuscripts at

http://www.hindawi.com
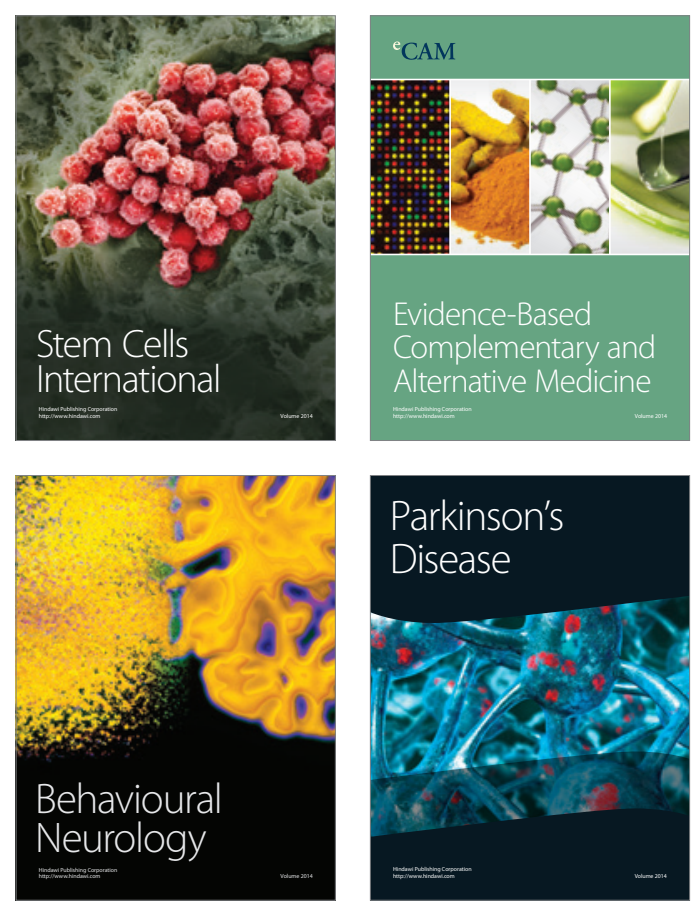

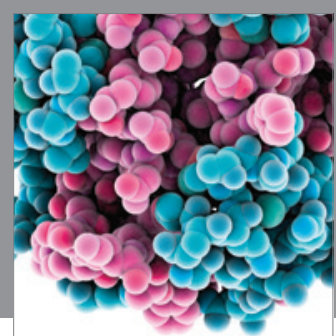

Journal of
Diabetes Research

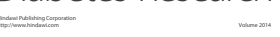

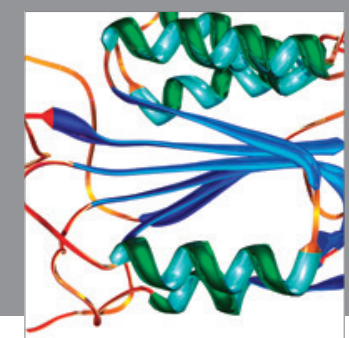

Disease Markers
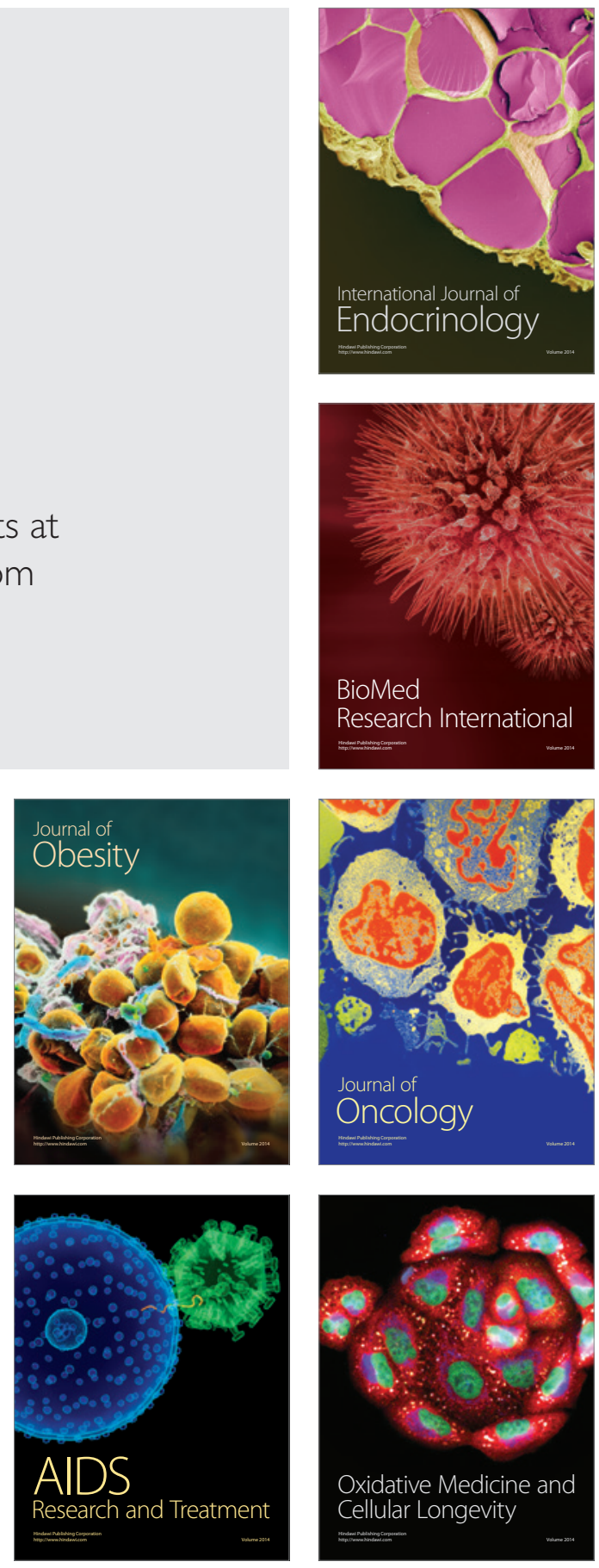